\title{
A quantitative morphometric comparison of cockpit and doline karst landforms
}

\author{
LIANG Fuyuan", "DU Yunyan², GE Yong' ${ }^{2}, \mathrm{LI} \mathrm{Ce}^{3}$ \\ 1. Department of Geography, Western Illinois University, Macomb IL 61455, USA; \\ 2. State Key Laboratory of Resources and Environmental Information System, Institute of Geographic Sciences \\ and Natural Resources Research, CAS, Beijing 100101, China; \\ 3. The Institute of Remote Sensing and Digital Earth, CAS, Beijing 100094, China
}

\begin{abstract}
This study presented a quantitative comparison of cockpit and doline karst by examining the numbers and characteristics of typical types of landform entities that are developed in Guilin (Guangxi, China), La Alianza (PR, USA), Avalton (KY, USA), and Oolitic (IN, USA). Five types of landform entities were defined: isolated hill (IH), clustered hills (CHs), isolated sinkhole (IS), clustered sinkholes (CSs), and clustered hills with sinkholes (CHSs). An algorithm was developed to automatically identify these types of landform entities by examining the contour lines on topographic maps of two cockpit karst areas (Guilin and La Alianza) and two doline karst areas (Oolitic and Avalton). Within each specific study area, the $\mathrm{CHSs}$ is the least developed type yet with a larger size and higher relief. The IH and IS entities are smaller in size, lower in relief, and outnumber their clustered counterparts. The total numbers of these types of entities are quite different in cockpit and doline karst areas. Doline karst is characterized by more negative (IS and CSs) than positive (IH and IHs) landforms and vice versa for cockpit karst. For example, the Guilin study area has 1192 positive landform entities in total, which occupy $9.81 \%$ of the total study area. It has only 622 negative landform entities occupying only $3.91 \%$ of the total study area. By contrast, the doline karst in Oolitic has 130 negative while only 10 positive landform entities. The positive and negative landforms in Oolitic occupy $12.68 \%$ and $2.61 \%$ of the total study area, respectively. Furthermore, average relief and slope of the landform entities are much higher and steeper in the cockpit karst than the doline karst areas. For instance, the average slope of $\mathrm{CHs}$ in Alvaton is 3.90 degrees while it is 19.78 degrees in La Alianza. The average relief of CSs is $4.07 \mathrm{~m}$ and $34.29 \mathrm{~m}$ in Oolitic and Guilin respectively. Such a difference within a specific area or between the cockpit and doline karst may reveal different controls on the development of karst landscape.
\end{abstract}

Keywords: cockpit; doline; contours; morphometric characteristics; topographic map; karst

Received: 2014-02-16 Accepted: 2014-07-12

Foundation: The State Key Laboratory of Resources and Environmental Information System, No.088RA500KA; National Natural Science Foundation of China, No.41071250; No.41371378

Author: Liang Fuyuan, PhD, specialized in geomorphology and GIS research. E-mail: F-Liang@wiu.edu

"Corresponding author: Du Yunyan, PhD, E-mail: duyy@lreis.ac.cn 


\section{Introduction}

The Earth's surface is covered by different types of landforms, which can be recognized and distinguished by their distinct dimensions and the statistical frequency of their geomorphic attributes (MacMillan and Shary, 2009). The topography of a specific landform type usually defines its geomorphic form and represents the interactions of climatic, geological, and other surface processes that have acted on it over time (Bishop et al., 2003). Delineation and extraction of different types of landforms and examining their distinct geomorphometric characteristics thus can help geomorphologists better understand Earth's surface processes and landscape evolution.

Landform classes or individual landforms can be segmented or extracted from the continuous Earth's surface based on their geomorphometric characteristics (Evans, 1972). Traditionally, both continuous landform classes and discrete landforms were manually delineated from topographic maps with visual aids of aerial photographs in appropriate scales (Evans, 2012; Fenneman, 1938; Hammond, 1954; Williams, 2004). Many methods to landform classification have been developed recently owing to the advances in geospatial technologies and wide availability of digital elevation data. Studies have been reported to automatically partition the continuous earth surface into different landform classes at various scales (e.g. Iwahashi and Pike, 2007; MacMillan et al., 2004; Minár and Evans, 2008; Zhou et al., 2010; Cheng et al., 2011; Chai et al., 2009). By contrast, development of methods to automatically delineate individual landforms significantly lagged behind (Evans, 2012) with only a few successful attempts. For example, Clark et al. (2009) successfully delineated drumlins in an area close to Loch Lomond in Scotland from a NextMap 5-m DEM. Alluvial fans in the Death Valley in the southwestern USA were extracted from a 90-m-posting DEM and 30-m Landsat TM satellite images (Miliaresis and Argialas, 2000). Van Asselen and Seijmonsbergen (2006) also successfully extracted individual landforms such as alluvial fans, fluvial terraces, incised channels, and talus slopes from 1-m Lidar-derived DEMs. For landform mapping, Evan (2012) advocated an idea to first delineate specific landforms and then classify the "leftover." However, he also argued that such a classification procedure is challenging as boundaries of specific landforms are usually fuzzy and strongly related to the scale at which the Earth's surface was studied.

Landform classification has become one of the research foci of both geomorphologists and soil/ecology scientists, yet from different perspectives. Soil/ecology scientists focus more on the identification of landform elements (MacMillan et al., 2000, 2004; Minár and Evans, 2008) and individual slope segments which tend to have a restricted range of moisture, soil type, and hydrological characteristics. Thus mapping landform elements and slope segments helps scientists better understand the influences of topography on biophysical components. The landform elements can then be grouped into different landform types (MacMillam, 2004). By contrast, geomorphologists probably are more interested in identifying landforms as discrete geomorphic units (MacMillan and Shary, 2009, and references therein). Such units, with or without connecting tissue, tend to have their own morphometric characteristics and thus may reflect the surface processes that have acted on them over time. Extraction of distinct geomorphic units or landforms, also known as geomorphological mapping in geomorpholoy, is valuable for geomorphologists to understand the development and evolution of specific types of landforms. 
For decades geomorphologists have been developing systems of landform classification, which are usually hierarchical and with more sub-divisions at finer scales (Hammond, 1954; Hengl and Rossiter, 2003; Meijerink, 1988). Recently, automated landform classification methods have been developed to replicate these systems, under which specific landforms were further delineated. At the landform type level, the continuous Earth's surface is usually segmented into plateau, mountains, hills, valleys, and plains etc. However, for a landscape with a specific type of landforms, mapping a special and specific type of landforms probably is more of significance in understanding landform development and evolution. For example, a fluvial geomorphologist would prefer to have a map showing alluvial fans, fluvial terraces, and incised valleys as Van Asselen and Seijmonsbergen (2006) did in their research. A glaciologist may be more interested in a map showing the specific landforms such as drumlin and cirques etc. Thus from a geomorphologist's perspective, it is probably more appropriate and important to determine and define what specific landforms are about to be mapped rather than simply presenting general landforms such as peaks, valleys and plains. The definitions must also be operational for digital landform classification and geomorphic mapping. That is to say, the specific landforms to be mapped must have their own geomorphometric signature (Pike, 1988) and are ready to be delineated and extracted from digital topographic data.

From a methodological perspective, specific landforms were mainly extracted from DEMs (Van Asselen and Seijmonsbergen, 2006; Clark et al., 2009; Miliaresis and Argialas, 2000). There were only a few attempts to examine contours on topographic maps (Cronin, 2000; Kweon and Kanade, 1994; Tribe, 1991) to delineate general the specific landforms such as hills, valleys, peaks, pits and ravine. To our knowledge, no attempts have been made to delineate and extract specific landform entities. This paper presented an automated method to extract typical karst landforms on Earth's surface by examining the contour lines on digital topographic maps. The method was applied to study two cockpit and two doline karst areas in China and the USA. Difference in total number of each type of landform entity within a specific study area and between different study areas is significant and may provide some new insights into the possible controls in the development and evolution of karst landforms.

\section{Methodology}

Karst refers to a special style of landscape containing landforms on and beneath the Earth's surface. Obviously only surface karst landforms can be mapped from DEMs. Though karst landforms were also developed in extreme climate conditions, most typical surface karst landforms were developed in humid regions (Ford and Williams, 2007). It is a formidable task to develop a comprehensive classification scheme for karst landforms as they vary significantly in their morphometric characteristics and origins. One way to study karst landforms is to examine individual landforms, such as karren, doline, poljes, residual hills, and valley (Ford and Willams, 2007). These individual landforms can be categorized into landforms with either positive or negative relief (White, 1988). Karst landforms may also be categorized into either exposed or buried landforms (Veni, 2002). Nevertheless, doline karst and cockpit karst are the two types of landforms that are well distributed and studied. Doline karst refers to rolling plains that are mainly scattered with individual or clustered sinkholes. 
By contrast, cockpit karst is characterized by star-shaped sinkholes that are surrounded by steep and rounded residual hills. Such a verbal and vague description of the difference between doline karst and cockpit karst actually has become an obstacle of digitally mapping karst landscape. Current existing maps of surface karst landforms were mainly produced manually (Gao et al., 1986; Zhu, 1988) with aids of topography maps and aerial photographs. There are few attempts to digitally classify surface karst landscapes except the recent efforts of mapping the tower karst and cockpit karst landscapes in Guilin (Liang and $\mathrm{Xu}, 2014$ ). They argued that mapping surface karst landscapes is valuable for karst geomorphologists to understand the factors that are controlling development of different types of karst landforms. It is also important for DEM preparation as cockpit karst tends to have natural depressions which should be retained rather than simply filled.

The major purpose of this study is to develop a method which can be used to quantitatively describe the difference between doline and cockpit karst in terms of their morphometric characteristics. Continuous karst landscapes were delineated into discrete landform entities, which were then quantitatively compared to reveal the morphometric difference between cockpit and doline karst. In this study, we delineated five types of specific karst landforms (Figure 1), including isolated hill (IH), isolated sinkhole (IS), clustered hills (CHs), clustered sinkholes (CSs), and clustered hills with sinkholes (CHSs). The IH and IS entities refer to the isolated residual hill and sinkhole respectively. Within each IH or IS, there is only one peak or sink. Geometrically, an IS entity is a small to intermediate enclosed depression, which is deemed as the diagnostic karst feature as karst is always developed in the areas where sinkholes are found (Ford and Williams, 2007). A CSs entity is a cluster of sinkholes that coalesce into a large closed depression while a $\mathrm{CHs}$ entity consists of residual hills that share a common bedrock base. A CHSs entity is a cluster of residual hills with one or more sinkholes within the cluster. Such a classification scheme is actually a reflection of

(a) Isolated hill

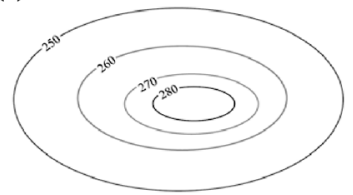

(c) Isolated sinkhole

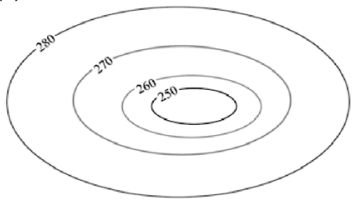

(e) Clustered hills withsinkholes

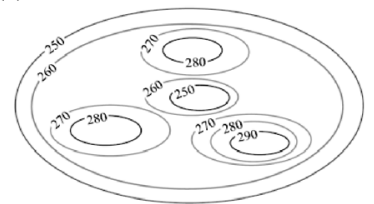

Figure 1 Exemplary clusters of closed contour lines show isolated hill (a), clustered hills (b), isolated sinkhole (c), clustered sinkholes (d) and clustered hills with sinkholes (e) the sequential products of karst landform evolution (Grund, 1914).

In this study, these five types of landform entities were delimitated by examining contour lines on topographic maps (Liang and Du, 2013). In fact, these landform entities are either an individual or a cluster of depressions/residual hills. On a topographic map, depressions and hills are represented by closed contour lines (CCLs). Each type of these landform entities is thus represented by a cluster of CCLs, depending upon the contour interval of the topographic maps and the relief of a specific landform. In this study, we first identified the outmost CCL, which contains at least another CCL 
but is not contained by any other CCLs. The outmost CCL was used as the boundary of a landform entity. Thus a specific landform was represented by a cluster of CCLs including an outmost CCL. Types of landform entity were then determined by studying the spatial relationships of CCLs within the outmost CCL as well as the changes of their elevations.

Every CCL cluster was then converted to an acyclic graph, with one node representing a specific CCL. The outmost CCL is represented by a root node. A leaf node is used to represent the innermost CCL, which contains no other CCLs but is contained by at least one CCL. If a CCL contains at least two other CCLs with a same elevation, it is defined as a branch node in the acyclic graph. All other CCLs within the outmost CCL are represented by middle nodes. Given that, the aforementioned landform entities can be described by following representative scenarios (Figure 2). Both IH and IS have no branch nodes but only one leaf node connecting to the root node. Middle nodes may exist depending upon the contour interval and landform relief. From the root node to the leaf node, elevation gradually increases for an IH entity (Figure 2a) while decreases for an IS entity (Figure 2c). An acyclic graph with at least one branch node represents $\mathrm{CHs}$ (Figure 2b) if the elevation gradually increases from the root to the leaf node; and a CSs entity (Figure 2d) if the elevation is gradually decreasing. If there are at least one leaf or middle node having elevation higher and another one having elevation lower than the branch, middle, or root node that right connects to them, the graph defines a CHSs entity (Figure 2e). An algorithm was developed to automatically screen all clusters of CCLs and identify what specific types of landform entities they represent. Once landform entities were delimitated, their total number, area, relief, and average slope were calculated in ArcGIS. Results were then summarized and compared within a specific study area and between different study areas.

(a) $\mathrm{IH}$

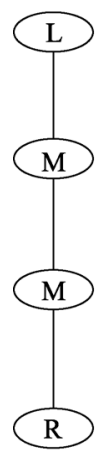

R Root node (b) $\mathrm{CHs}$

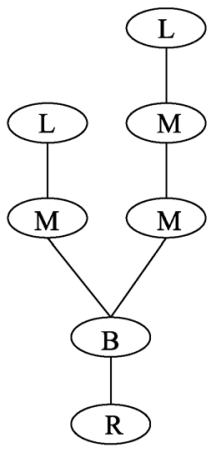

(M) Middle node (c) IS

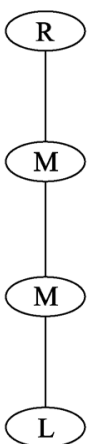

(d) CSs

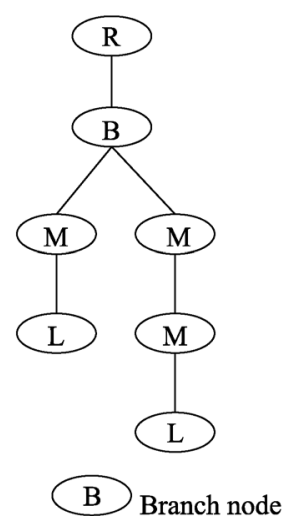

(e) CHSs

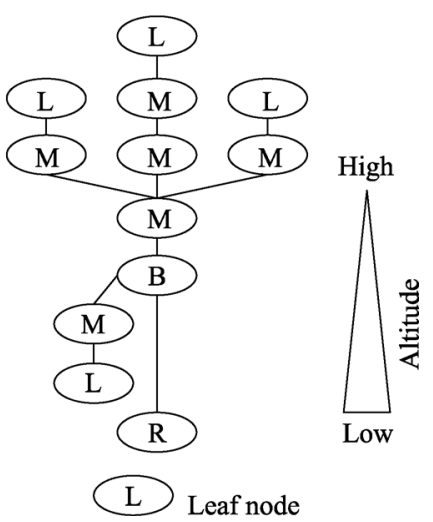

Figure 2 Representative acyclic graphs showing the typical types of surface karst landform entities

\section{Study areas and data}

\subsection{Study areas}

The method was used to delineate surface karst landforms in two cockpit karst areas (Guilin, Guangxi and La Alianza, PR) and two doline karst areas (Alvaton, KY and Oolitic, IN) (Figure 3). The study areas are bounded by natural breaklines of topograpy, such as river 
channels or ridges except the Guilin study area to ensure landform entities were included in the study as a whole. A rectangle was first drawn to outline the Guilin study area. The boundary was then refined by annexing the areas defined by the outmost CCLs of all landform entities that are located along the boundary of the study area (Figure 3a). Guilin area is well-known for its spectacular tower and cockpit karst landscapes, which were mainly developed on a plain. The tower karst is characterized by isolated and clustered residual hills rising from a plain while the cockpit karst is featured by clustered residual hills surrounded by depressions. La Alianza in Puerto Rico is also decorated by similar peak clusters in the south while generally replaced by isolated and clustered residual hills/sinkholes in the north. Unlike in the Guilin area, karst landscapes in Puerto Rico are developed on a slope generally dipping from south to north. Alvaton and Oolitic are both located on a rolling karst plain packed by small to intermediate isolated and clustered sinkholes.

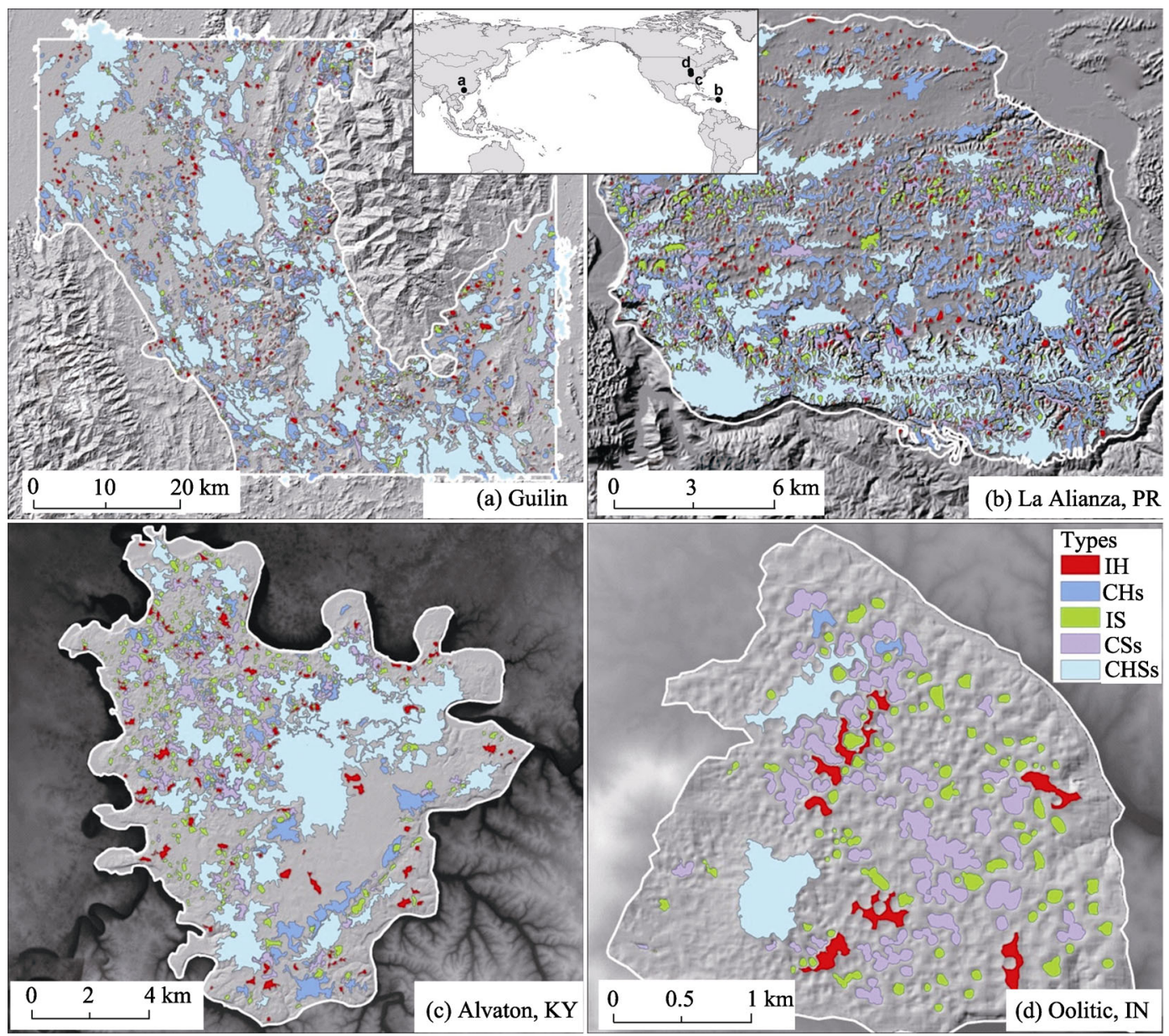

Figure 3 Delimitation results atop of hillshaded DEMs of Guilin, China (a), La Alianza, PR (b), Alvaton, KY (c), and Oolitic, IN (d)

\subsection{Data}

Landform entities in the cockpit and doline karst areas were delimitated from 30-m and $10-\mathrm{m}$ posting DEMs respectively. These DEMs are the best topographical data available to 
our study areas. The 30-m posting DEM of Puerto Rico was actually prepared based on the La Alianza 7.5-minute topographic quadrangle mapped by the United States Geologic Survey (USGS) at a contour interval of $10 \mathrm{~m}$. The Digital Line Graphs (DLG) were not used in this study as this research delineated landform entities by studying the topological relationships among CCLs. However, the DLG of La Alianza quadrangle has some open contour lines which are supposed to be closed due to aesthetic reasons. These contour lines are mainly found in the area with very steep slopes, which are one of the characteristics of cockpit karst in Jamaica (Lyew-Ayee et al., 2007) and in Guilin (Tang and Day, 2000). In this study, we generated contours at a $10-\mathrm{m}$ contour interval from the USGS DEM. The contours match well with those on the topographic maps and no closed contours were left open. The DEM of Guilin area was derived from a pair of stereo images (band $3 n$ and $3 b$ ) acquired by Advanced Spaceborne Thermal Emission and Reflection Radiometer (ASTER) as described in Liang et al. (2011). Accuracy of the ASTER DEM meets the requirement of morphometric analysis of the cockpit karst in southern China (Liang et al., 2011). Contours were generated from this DEM at an interval of $10 \mathrm{~m}$. For the doline karst areas, contours were derived from 10-m posting USGS DEMs at an interval of 10 feet $(0.304 \mathrm{~m})$. In fact, the $10-\mathrm{m}$ and 10 -foot contour intervals are determined by the spatial resolution of DEMs from which the contour lines were produced. Extracting contour lines with smaller intervals, though it is practical in technique, is not able to show more details of the topography and thus is not appropriate. This study also used geologic maps to erase non-karst topography in our four study areas.

\section{Results and discussion}

\subsection{Classification results}

Delimitation results are shown atop of hillshaded DEMs of our four study areas (Figure 3). Totally 1985, 2044, 592, and 142 landform entities were identified in Guilin, La Alianza, Alvaton, and Oolitic respectively (Table 1). These entities account for 46.64\%, 37.63\%, $37.10 \%$ and $19.86 \%$ of the total area of our four study areas respectively.

Table 1 Total number and occupying area of each type of landform entity in our four study areas

\begin{tabular}{|c|c|c|c|c|c|c|c|c|c|}
\hline Study area & $\begin{array}{c}\text { Type of } \\
\text { landscape }\end{array}$ & $\begin{array}{c}\text { Total area } \\
\left(\mathrm{km}^{2}\right)\end{array}$ & $\begin{array}{l}\text { Landform } \\
\text { entities }\end{array}$ & $\mathrm{IH}$ & $\mathrm{CHs}$ & IS & $\mathrm{CSs}$ & CHS & Total \\
\hline $\begin{array}{l}\text { Guilin, } \\
\text { Guangxi, }\end{array}$ & \multirow{4}{*}{$\begin{array}{c}\text { Cockpit } \\
\text { karst }\end{array}$} & \multirow{2}{*}{2537.14} & Number & 865 & 327 & 503 & 119 & 171 & 1985 \\
\hline China & & & Area (\%) & 3.10 & 6.71 & 1.86 & 2.05 & 32.91 & 46.64 \\
\hline \multirow{2}{*}{$\begin{array}{c}\text { La Alianza, } \\
\text { PR, USA }\end{array}$} & & \multirow{2}{*}{278.72} & Number & 819 & 520 & 455 & 159 & 91 & 2044 \\
\hline & & & Area (\%) & 3.01 & 10.77 & 2.60 & 3.21 & 18.04 & 37.63 \\
\hline \multirow{2}{*}{$\begin{array}{c}\text { Alvaton, KY, } \\
\text { USA }\end{array}$} & \multirow{4}{*}{$\begin{array}{c}\text { Doline } \\
\text { karst }\end{array}$} & \multirow{2}{*}{149.51} & Number & 103 & 31 & 320 & 103 & 35 & 592 \\
\hline & & & Area (\%) & 2.22 & 3.79 & 3.09 & 3.91 & 24.08 & 37.10 \\
\hline \multirow{2}{*}{$\begin{array}{c}\text { Oolitic, IN, } \\
\text { USA }\end{array}$} & & \multirow{2}{*}{9.72} & Number & 8 & 2 & 85 & 45 & 2 & 142 \\
\hline & & & Area $(\%)$ & 2.27 & 0.34 & 4.01 & 8.67 & 4.58 & 19.86 \\
\hline
\end{tabular}

There is a significant difference in the total number of each type of landform entity between the cockpit karst and doline karst areas. First of all, positive landforms (IH and CHs) 
outnumber negative landforms (IS and CSs) in the cockpit karst areas. By contrast, there are more negative landforms in the two doline karst areas. For example, totally there are 1192 $\mathrm{IH} / \mathrm{CHs}$ and only $622 \mathrm{IS} / \mathrm{CSs}$ in Guilin. By contrast, there are $423 \mathrm{IS} / \mathrm{CS}$ and only 134 $\mathrm{IH} / \mathrm{CHs}$ in Alvaton. Furthermore, the IH is the dominant type of landform entity in the cockpit karst areas and more than 800 individual entities were delineated in both Guilin and La Alianza. However, for the doline karst areas, the IS is the most developed type of landform entity and 302 and 85 entities were delineated in Alvaton and Oolitic respectively.

In terms of area, the CHSs entity is the dominant type in the two cockpit karst areas and occupies $32.91 \%$ and $18.04 \%$ of the total area of Guilin and La Alianza respectively. The IS is the least developed type of landform entity and only occupy $1.86 \%$ and $2.60 \%$ of the total study areas of Guilin and La Alianza, respectively. The doline karst is dominated by CHSs $(24.08 \%)$ in Alvaton while by CSs $(8.67 \%)$ in Oolitic in terms of the area they occupied. In the cockpit karst areas, the positive landforms are much well developed than the negative landforms in terms of their areas. The IH/CHs totally occupy $13.78 \%$ while the IS/CSs occupy only $5.81 \%$ of the total area of La Alianza. By contrast, the negative landforms tend to be more dominant than the positive landforms in the doline karst areas. The IS/CSs occupy $12.68 \%$ and $\mathrm{IH} / \mathrm{CHs}$ occupy only $2.61 \%$ of the total area of Oolitic. In Alvaton, the area occupied by negative landforms $(7 \%)$ is slightly more than that of the positive landforms $(6.01 \%)$ though the difference is not as significant as that in Oolitic.

There is also a significant difference of different types of landform entity within each specific area in terms of the total number and occupying area. In all four study areas, CHs and CSs are always fewer than their isolated counterparts. For example, Guilin has $327 \mathrm{CHs}$ and $865 \mathrm{IH}$. By contrast, there are only 119 CSs and 503 IS. Totally 103 IH and 320 IS were delineated in Alvaton respectively, while there are only $31 \mathrm{CHs}$ and $103 \mathrm{CSs}$ in this area.

\subsection{Characteristics of landform entities}

In all the four study areas, the larger landform entities tend to have higher relief (Figures 4-6). As illustrated in Figures 4b, 5b and 6, the CHSs are significantly bigger and have higher relief than the other four types of landform entities. In the cockpit karst areas, there is no significant difference between the average area and relief of IH and IS, though relief of $\mathrm{IH}$ in Guilin is slightly higher than that of the IS (Figure 4b). Average size of CHs and CSs are very similar in both La Alianza and Guilin. However, average relief of CHs is higher than that of CSs in both areas (Table 2). For example, average relief of CHs in Guilin is $80.21 \mathrm{~m}$, which doubles the relief of CSs $(34.29 \mathrm{~m})$. In Alvaton, there is no significant difference in the size of all types of landform entities except the CHSs. However, the CSs type tends to have higher relief than the CHs while the IS and IH have the lowest relief. By contrast, IH is the second largest landform entity and IS is the smallest type in Oolitic. Average area of CHs and CSs is almost the same in this area. In terms of relief, CSs is slightly higher than that of IH/IS/CHs.

Table 2 also lists the average and standard deviation of number of peak and sink, area, relief, slope, and range of slope of each landform entity type in our four study areas. The CHs type shows no significant difference in number of peaks per entity though the two cockpit karst areas tend to have slightly more peaks than the two doline karst areas. For CSs, there is also no significant difference in number of sinks per entity though the doline karst areas 

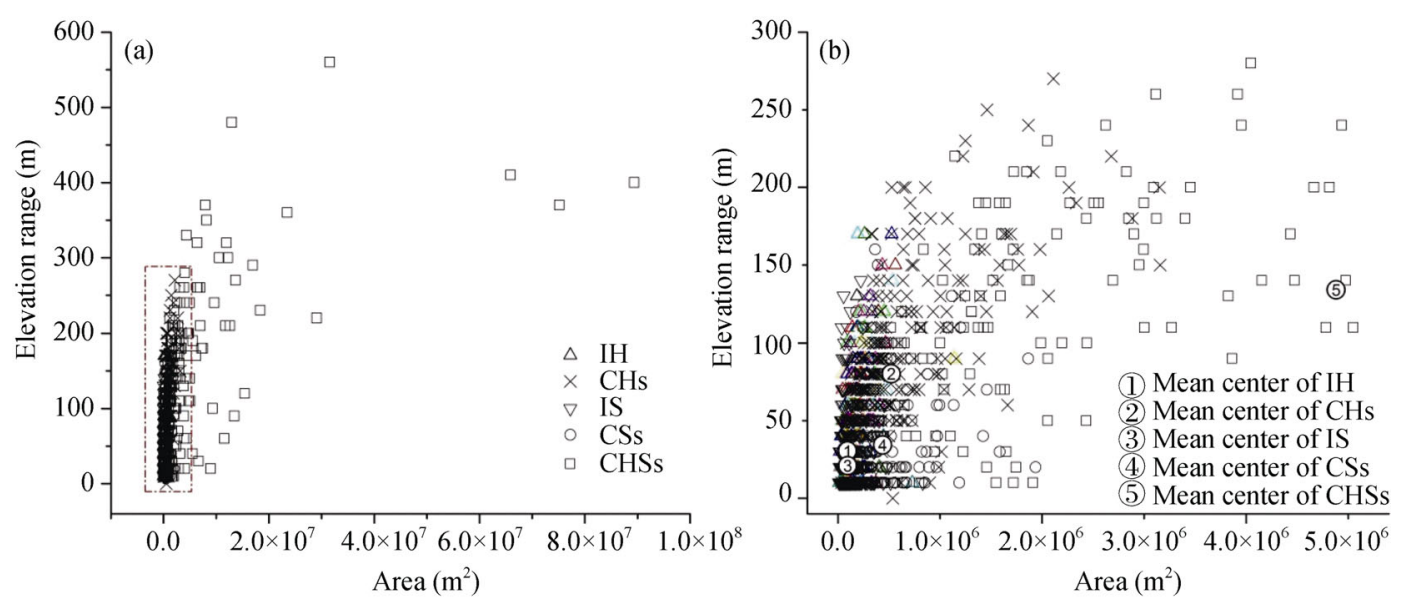

Figure 4 Positive relationships between average size and relief of each landform entity type in Guilin, Guangxi, China (a. all landform entities; b. the landform entities within the dash-line rectangle in Figure 4a)
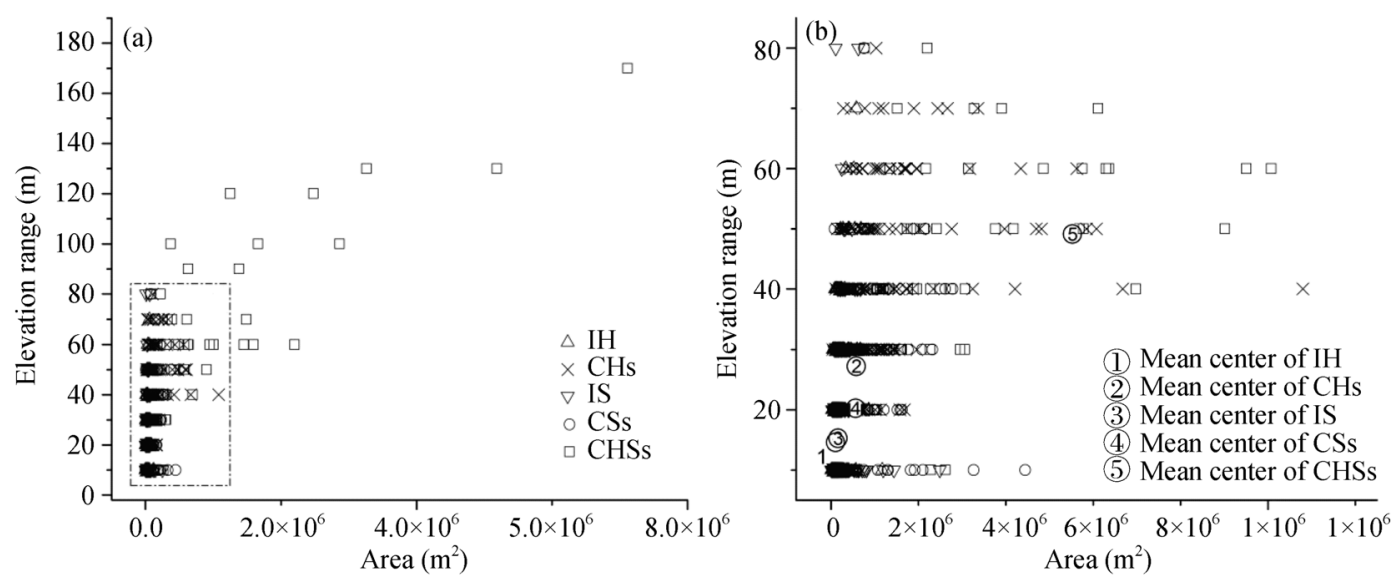

Figure 5 Positive relationships between average size and relief of each type of landform entity in La Alianza, PR (a. all landform entities; b. the landform entities within the dash-line rectangle in Figure 5a)
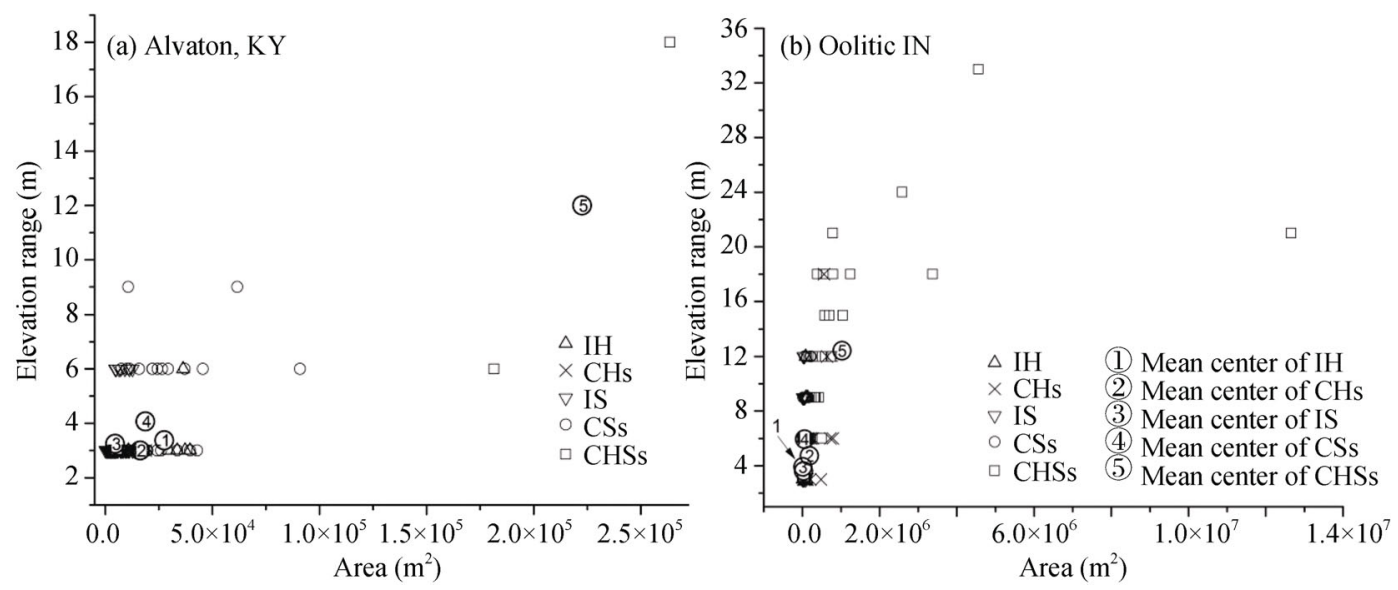

Figure 6 Positive relationships between average size and relief of each type of landform entity in Alvaton, KY (a) and Oolitic IN (b) 


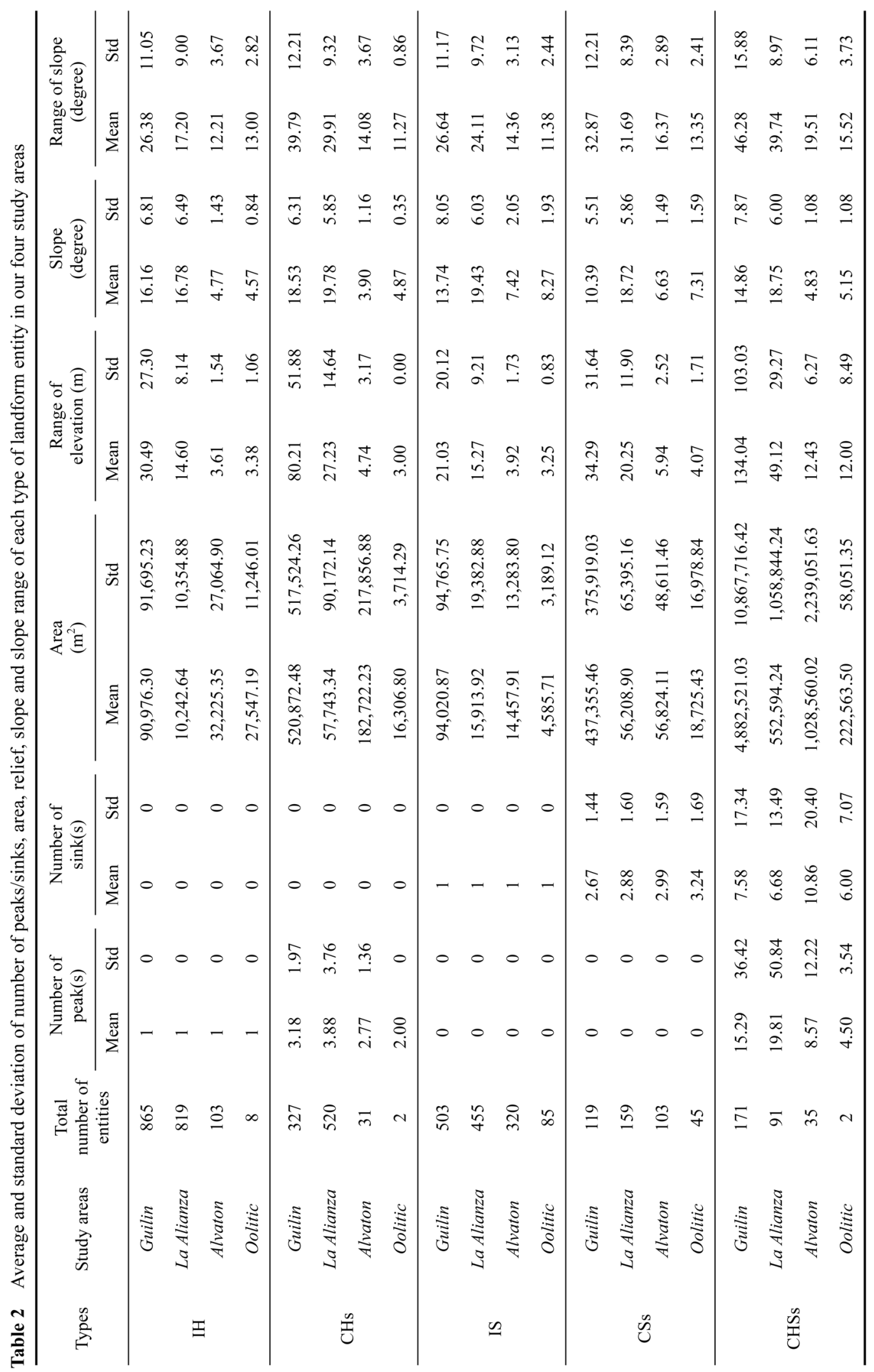


have slightly more sinks than the cockpit karst areas. The average number of peaks in CHSs of the two cockpit karst areas is significantly more than that of the two doline karst areas. For example, each CHSs entity in Guilin has 25.29 peaks in average while the doline karst in Oolitic has only 4.5 peaks. However, there is no significant difference in the average number of sinks between the cockpit karst and the doline karst, though the doline karst in Alvaton has slightly more sinks than the other three areas. The number of peaks is also positively related to the number of sinks in the CHSs in the two cockpit karst areas and a CHSs landform entity tends to have more peaks than sinks (Figure 7).
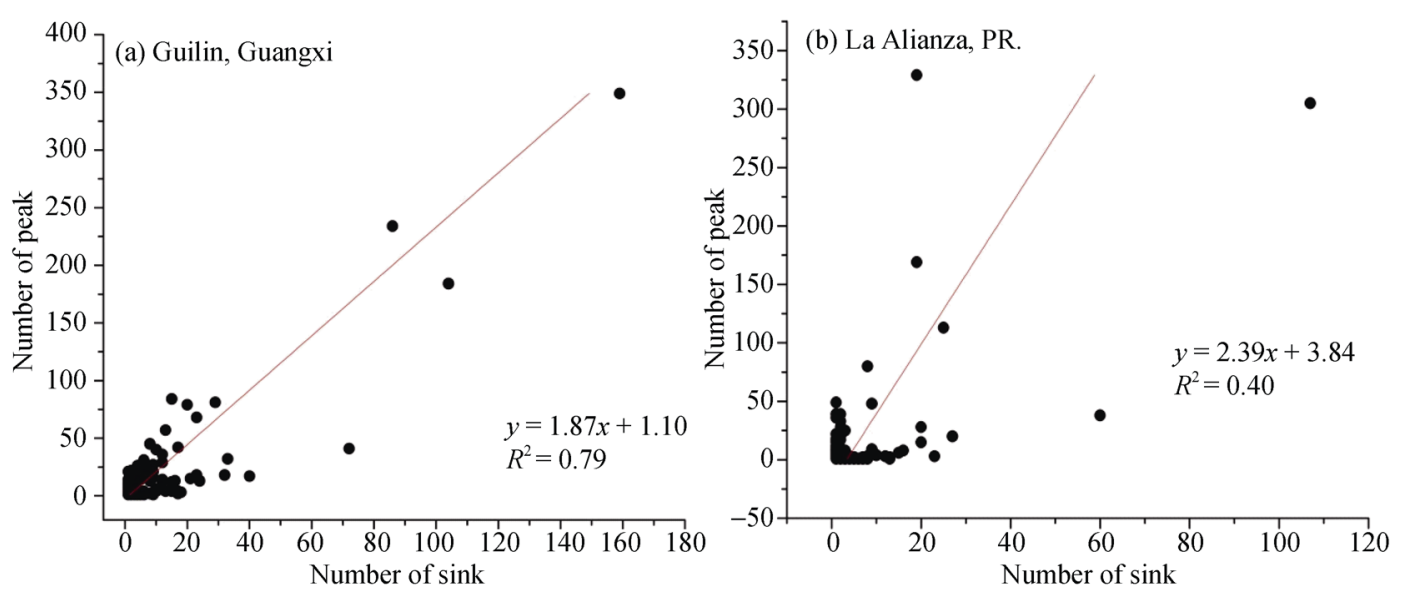

Figure 7 Positive relationships between the number of peaks and sinks within CHSs in cockpit karst areas of Guilin, China (a) and La Alianza, RR (b)

The landform entities in the cockpit karst areas are not always bigger than those in the doline karst areas. For example, the average size of CHs entity in Guilin is much bigger than those in the other three areas. In fact, Guilin is the only area that has bigger landform entities of all five types among our four study areas. For example, average area of IH in Guilin is $90,976 \mathrm{~m}^{2}$, which is significantly bigger that of $\mathrm{IH}$ in all other three areas. Average size of CHSs in Guilin is 4,882,521 $\mathrm{m}^{2}$ while the smallest CHSs in Oolitic is only $222,53 \mathrm{~m}^{2}$. The $\mathrm{CHs}$ in the cockpit karst of La Aliana is larger than that in the doline karst of Oolitic but smaller than the CHs in Alvataon. The IH entities in La Aliana are even smaller than those in the two doline karst areas.

The landform entities in the two cockpit karst areas always have higher average relief, slope, and range of slope than those in the two doline karst areas. For example the average relief of IH in Guilin area is $30.49 \mathrm{~m}$, which is much higher than the $3.38 \mathrm{~m}$ average relief in Oolitic. The average slopes of CHSs in Guilin and La Alianza are 14.86 and 18.75 degrees respectively. By contrast, they are only 4.83 and 5.15 degrees in Alvaton and Oolitic. The CSs also have a higher range of slope of 32.87 and 31.69 degrees in Guilin and La Alianza, which are both significantly higher than the 16.37 and 13.35 degrees slope ranges in Alvaton and Oolitic.

\subsection{Implication of landform development}

Karst geomorphologists have well recognized that our four study areas are decorated by 
cockpit and doline karst respectively. Classification results show that there are significant differences between the cockpit karst and doline karst in terms of the total numbers of different types of landform entities and their occupying areas. The cockpit and doline karst areas tend to have more positive and negative landforms respectively. Furthermore, the isolated hill or sink always outnumber their clustered counterparts in both cockpit and doline karst areas.

Such a difference is probably because these types of landforms entities were developed at different stages of karst evolution. In humid tropical or subtropical areas, dissolution of carbonate is the major process that creates different types of surface karst landforms. Usually IS is the first surface karst feature that is developed once subsurface conduits were established (Ford and Williams, 2007). Once a sinkhole commences to form, the centripetal focusing of runoff and hence further dissolution of carbonate encourages enlargement of the initial isolated sinkholes. Given enough time, this self-reinforcement process leads to coalescence of adjacent isolated sinkholes and clustered sinkholes are developed. As IS is always being developed in different evolution stages of karst landforms, it is not unexpected to find more IS than CSs in each specific study area.

With more carbonate being removed by the focusing dissolution within sinkholes, original carbonate block is bisected into chunks. Within the chunks, new IS may commence to form and existing CSs may continue to grow. With removal of more carbonate, residual hills surrounded by sinkholes maybe developed. CHs and then IH could be developed as the next sequential products when dissolution and erosion remove more carbonate. Yet IH could also be directly derived from the continuous growth and enlargement of IS or CSs (Ford and Williams, 2007; Zhu, 1988). Nevertheless, the IH tends to represent the last stage product of karst development as solution activity has removed most of the carbonate formation.

Ford and Williams (2007) argued that the morphometric characteristics of different landform entities may "throw up unexpected observations and stimulate fresh hypotheses" of karst landform development. However, extreme cautions should be used to infer landform evolution processes from morphometric analysis results themselves. Instead, morphometric forms of specific types of karst landform entities should be deemed as a product of the interactions among climate, lithology, and geohydrological settings (Ford and Williams, 2007). Discussion of how these factors shape the forms of different types of karst landforms entities in our four study areas is beyond the scope of this article. In future studies, it will be interesting to investigate the evolution of karst landscapes in these areas by comprehensively analyzing the relationship between their morphometric forms and climate, lithology and geohydrological settings.

\section{Conclusions}

Karst geomorphologists have well recognized the morphometric differences between cockpit and doline karst. Cockpit karst is characterized by residual hills that surrounded by deep depressions. By contrast, sinkholes developed across a rolling plain are the dominant landforms in doline karst areas. Quantitative difference between cockpit and doline karst is significant in terms of the total numbers and occupying areas of different types of landform entities that were identified in this study. 
(1) Negative landforms are more developed than positive landforms in doline karst areas. By contrast, cockpit karst has more positive landforms than their negative counterparts. Totally there are 1192 and 1339 positive landforms in Guilin and La Alianza, and only 622 and 614 negative landforms respectively. By contrast, there are 423 and 130 negative landforms but only 134 and 10 positive landforms in Alvaton and Oolitic respectively. Total area occupied by the positive landforms in cockpit karst is also more than that of the negative landforms. However, the doline karst tends to have more negative landforms than their positive counterparts in terms of the occupying area. For example, $12.68 \%$ of the total area of Oolitic is occupied by negative landforms while only $2.61 \%$ area is occupied by positive landforms.

(2) There are always more IH and IS than their clustered counterparts in each specific study area. For example, La Alianza has $819 \mathrm{IH}$ while only $520 \mathrm{CHs}$. There are 320 IS entities while only $103 \mathrm{CSs}$ entities in Alvaton. Such a difference may be because development of different types of landform entities was initiated at different stages of karst development.

(3) The relief and average slope of individual type of landform entity in cockpit karst areas tend to be higher and steeper than those of the doline karst areas. For example, average relief of CHSs in the cockpit karst of Guilin and La Alianza is $134.04 \mathrm{~m}$ and $49.12 \mathrm{~m}$, which are significantly higher than those in the doline karst of Alvaton $(12.43 \mathrm{~m})$ and Oolitic $(12.00 \mathrm{~m})$. Average slope of CHSs in the doline karst areas is less steeper than that of the cockpit karst. Such a difference may reflect the lithological and hydrological controls on the development of karst landscapes.

\section{References}

Bishop M P, Shroder J F et al., 2003. Remote sensing and geomorphometry for studying relief production in high mountains. Geomorphology, 55: 345-361.

Chai H, Zhou C, Chen X et al., 2009. Digital regionalization of geomorphology in Xinjiang. Journal of Geographical Sciences, 19(5): 600-614.

Cheng W, Zhou C, Chai H et al., 2011. Research and compilation of the Geomorphologic Atlas of the People's Republic of China (1:1,000,000). Journal of Geographical Sciences, 21(1): 89-100.

Clark C D, Hughes A L, Greenwood S L et al., 2009. Size and shape characteristics of drumlins, derived from a large sample, and associated scaling laws. Quaternary Science Reviews, 28: 677-692.

Cronin T, 2000. Classifying hills and valleys in digitized terrain. Photogrammetric Engineering and Remote Sensing, 66: 1129-1137.

Evans I S, 1972. General geomorphometry, derivatives of altitude, and descriptive statistics. Spatial Analysis in Geomorphology, 17-90.

Evans I S, 2012. Geomorphometry and landform mapping: What is a landform? Geomorphology, 137: 94-106.

Fenneman N M, 1938. Physiography of Eastern United States. New York: StatesMcGraw Hill Book Co.

Ford D C, Williams P, 2007. Karst Hydrogeology and Geomorphology. John Wiley \& Sons.

Gao D, Zhang S, Bi K et al., 1986. Research on Karst Landscapes in Southern Guizhou. Guiyang: Guizhou Peoples' Publishing House. (in Chinese)

Grund A, 1914. Der geographische Zyklus im Karst. Gesellschaft für Erdkunde, 52: 621-640.

Hammond E H, 1954. Small-scale continental landform maps. Annals of the Association of American Geographers, 44: 33-42.

Hengl T, Rossiter D G, 2003. Supervised landform classification to enhance and replace photo-interpretation in semi-detailed soil survey. Soil Science Society of America Journal, 67: 1810-1822.

Iwahashi J, Pike R J, 2007. Automated classifications of topography from DEMs by an unsupervised nested-means algorithm and a three-part geometric signature. Geomorphology, 86: 409-440. 
Kweon I S, Kanade T, 1994. Extracting topographic terrain features from elevation maps. CVGIP: image understanding, 59: 171-182.

Liang F, Brook G A, Shi Y, 2011. Mapping cockpit karst in southern China from ASTER stereo images: DEM validation and accuracy assessment. Carsologica Sinica, 30: 233-242.

Liang F, Du Y, 2013. An automated method to extract typical karst landform entities from contour lines on topographic maps. In: Proceedings of Geomorphometry 2013, Nanjing, China, 46-49.

Liang F, Xu B, 2014. Discrimination of tower-, cockpit-, and non-karst landforms in Guilin, southern China, based on morphometric characteristics. Geomorphology, 204: 42-48.

Lyew-Ayee P, Viles H A, Tucker G E, 2007. The use of GIS-based digital morphometric techniques in the study of cockpit karst. Earth Surface Processes and Landforms, 32: 165-179.

MacMillan R A, Jones R K, McNabb D H, 2004. Defining a hierarchy of spatial entities for environmental analysis and modeling using digital elevation models (DEMs). Computers, Environment and Urban Systems, 28: 175-200.

MacMillan R A, Pettapiece W W, Nolan S C et al., 2000. A generic procedure for automatically segmenting landforms into landform elements using DEMs, heuristic rules and fuzzy logic. Fuzzy Sets and Systems, 113: 81-109.

MacMillan R A, Shary P A, 2009. Landforms and landform elements in geomorphometry. Developments in Soil Science, 33: 227-254.

Meijerink A M J, 1988. Data acquisition and data capture through terrain mapping units. ITC-Journal, 1: 23-43.

Miliaresis G C, Argialas D P, 2000. Extraction and delineation of alluvial fans from digital elevation models and Landsat Thematic Mapper images. Photogrammetric Engineering and Remote Sensing, 66: 1093-1101.

Minár J, Evans I S, 2008. Elementary forms for land surface segmentation: The theoretical basis of terrain analysis and geomorphological mapping. Geomorphology, 95: 236-259.

Pike R J, 1988. The geometric signature: Quantifying landslide-terrain types from digital elevation models. Mathematical Geology, 20: 491-511.

Tang T, Day M J, 2000. Field survey and analysis of hillslopes on tower karst in Guilin, southern China. Earth Surface Processes and Landforms, 25: 1221-1235.

Tribe A, 1991. Automated recognition of valley heads from digital elevation models. Earth Surface Processes and Landforms, 16: 33-49.

Van Asselen S, Seijmonsbergen A C, 2006. Expert-driven semi-automated geomorphological mapping for a mountainous area using a laser DTM. Geomorphology, 78: 309-320.

Veni G, 2002. Revising the karst map of the United States. Journal of Cave and Karst Studies, 64(1): 45-50.

White W B, 1988. Geomorphology and Hydrology of Karst Terrains. New York: Oxford University Press.

Williams P, 2004. Polygonal karst and palaeokarst of the King Country, North Island, New Zealand. Zeitschrift für Geomorphologie Suppl., 136: 45-67.

Zhou Y, Tang G A, Yang X et al., 2010. Positive and negative terrains on northern Shaanxi Loess Plateau. Journal of Geographical Sciences, 20(1): 64-76.

Zhu X, 1988. Guilin Karst. Shanghai: Shanghai Scientific and Technical Publishers. (in Chinese) 